\title{
Information for Research in Developing Countries: Information Technology - Friend or Foe?
}

\section{by Subbiah Arunachalam}

Editor's Note:This article has been extracted from the paper awarded second place in the ASIST SIG/III 2002 International Paper Competition. See Inside ASIST in this issue for information about the 4th annual International Paper Competition.

Subbiah Arunachalam is with the M S Swaminathan Research Foundation at Third Cross Street, Taramani, Chennai 600 113, India, and can be reached by e-mail at subbiah_a @hotmail.com

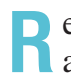
esearch or production of knowledge is at once an intensely personal and social activity. The quest for exploring unknown territories - the loneliness of a long-distance runner - is the personal aspect. But aggregation and advancement of knowledge takes place by collective efforts of researchers around the world. In the production of new knowledge scientists use what is already known. That pattern is why we need huge - and expensive libraries. Moreover, generation of knowledge is only one part of the research process. For knowledge to be useful, it should be shared with other researchers and communicated, in a suitable format, to different users/stakeholders. Scientists in developing countries are terribly handicapped in both generation and sharing.

\section{Doing Science in the Developing World}

Even when both information and communication were entirely mediated by the printed word, there was a big gap between the richer and poorer countries that increased with the passage of time. For example, in the 1920s, 30s and 40s, India did rather well in science. It was then that men of the calibre of Srinivasa Ramanujan ("the man who knew infinity," as the award-winning book by Robert Kanigel referred to him), C. V. Raman (India's first Nobelist in science), Meghanad Saha (known for his work on thermal ionization) and Jagdish Chandra Bose (who many believe was ahead of Marconi in recognizing the existence of radio waves) performed their world class work.
In those days, there were very few journals. The journals, most of them published in the West, took a few months to arrive in India by sea, and to that extent Indian scientists were behind their Western counterparts in the matter of access to information. In contrast by the 1960s and 70s, there were approximately 50,000 research journals and many libraries in India could subscribe at best only to a few hundreds. Also, for some reason, interlibrary lending never did pick up in India (and most other parts of the developing world). The net result was that scientists in developing countries suffered a great deal of relative disadvantage compared to their Western counterparts.

Today many institutions in developing countries cannot afford to maintain good libraries. Most libraries in sub-Saharan Africa have not subscribed to any journal for years. "If scientists in many African universities often have to rely on what they are told by newspapers, by friends or Time magazine, how can they ever compete with scientists in USA and Western Europe when there is such a vast difference in their ability to access information, either through print media or electronically?" asks Seun Ogunseitan, the Nigerian journalist-turnedinformation provider.

Indian Institute of Science, Bangalore, the bestfunded library among all Indian institutions of higher education, has an annual library budget of approximately Rs 90 million (about $\$ 1.8$ million). Only a handful of Indian libraries have a budget of around Rs 10 million (about $\$ 200,000$ ) - peanuts 
compared to the acquisition budgets of even moderate university libraries in the United States. Even in the West, universities and research institutions are facing a major serials crisis. The cost of journals is escalating at a rate much higher than the general inflation rate. The last few years have witnessed the emergence of many initiatives to meet it, and some of them are eminently advantageous to scientists and scholars in the developing world. We will look at them in a moment.

\section{Technology Divides}

If escalating costs of print journals has made life miserable for scientists in developing countries in particular, and scholars in social sciences and humanities, the advent of electronic sources of information has made the situation even worse. It is in the nature of any new technology to exacerbate the existing divide between the rich and the poor. The newer and more potent the technology, the greater its ability to increase the inequalities.

The rapid changes that are taking place in the ways new information is published, stored, disseminated and retrieved using the rapidly advancing information and communication technologies have exacerbated the relative deprivation suffered by researchers in the developing world. The new information and communication technologies (ICTs) have not just made each operation faster, but have brought about a greater synergy between these operations in ways unthinkable in the earlier era mediated by print on paper.

Furthermore, when many journals started publishing electronic versions they started accepting manuscripts electronically and got the papers reviewed electronically. Many developing country scientists, who did not have access to personal computers, e-mail and the Internet, could neither submit their papers to these journals nor read them or act as referees. The irony is that one does not receive papers to referee not because he is not considered good enough, but because he is not connected by the right technology!

Let me give one more example - how lack of access to the right kind of technology can jeopardize one's chances for participation in research programs. More R\&D collaborations are developing with Internet-facilitated innovations such as virtual research laboratories and the simultaneous use of distributed virtual data banks by researchers around the globe, and grids, which depend in a fundamental way on access to high bandwidth networks. Most researchers in developing countries, even those who are eminently qualified to take part in such collaboration, are excluded simply because they do not have access to the right technology.

Thus the new ICTs, left to their own devices, will surely widen the knowledge divide or the disparities in people's capacities to do research and their ability to use them to their advantage. Thanks to men like Gandhi, Martin Luther King, Nelson Mandela and Desmond Tutu, we have abolished apartheid based on skin color, but we are letting the new ICTs create a new kind of apartheid based on information access.

\section{Lack of Visibility}

Inadequate access to literature or information is not the only problem facing scientists in developing countries. An equally important problem is that research carried out in developing countries lacks visibility. Nobody notices it. Nobody quotes it. The same is true for most journals published in developing countries. Very few papers published from developing countries become citation classics or find a place in the list of key papers in an emerging research front. After years of doing research under rather difficult conditions, one still finds oneself in the category of also-rans.

\section{The Gap Is Widening}

Clearly, the advent and rapid development of the new information and communication technologies have not really helped scientific research in the developing countries. The Internet access gap between the rich and the poor areas of the world is not only large, but growing, according to the (U.S.) National Science Foundation's Science and Engineering Indicators 2002. In 1997, Internet host penetration rates in North America were 267 times greater than rates in Africa; by October 2000, the gap had grown to a multiple of 540. History has shown us that any technology will exacerbate the existing divides. And ICTs have exacerbated the existing inequalities in the world of science in such a short time. But, in my opinion, one does not have to lose hope.

As demonstrated by the award-winning Information Village project of the M S Swaminathan Research Foundation in India, if intelligently and innovatively used, the very same information and communication technologies can become allies in our efforts to bridge the divides (Arunachalam, S. 2002. Reaching the unreached: How can we use ICTs to empower the rural poor in the developing world through enhanced access to relevant information? IFLA General Conference, Glasgow, 18-24 August 2002. www.ifla.org/IV/ifla68/prog02.htm). Let us see how.

\section{Efforts Afoot}

The past few years have witnessed several developments that could make access to information for scientists in the developing world a lot more affordable. These include initiatives promoted by scientists, libraries, publishers, academies and societies. Brief descriptions of a few of them follow.

\section{Public Library of Science (www.publiclibraryofscience.org)}

The Public Library of Science, a grassroots initiative by scientists, is a non-profit organization of scientists committed to making the world's scientific and medical literature freely accessible to scientists and to the public around the world for the benefit of scientific progress, education and the public good. The aim is to establish international online public libraries of science that will archive and distribute the complete contents of published scientific articles and foster the development of new ways to search, interlink and integrate information. 


\section{In the very near future, the print versions of journals will not be the true archivers. The e-print archives... offer built-in insurance against possible loss of archived} material due to unforeseen calamities (such as natural disasters or system failures at any one location).

As a step toward these goals, scientists around the world have been circulating an open letter urging publishers to allow the research reports that have appeared in their journals to be distributed freely by independent, online public libraries of science. More than 30,000 people from 177 countries have signed the open letter, as of June 15, 2002. This initiative has prompted some significant and welcome steps by many scientific publishers toward freer access to published research, but in general these steps have fallen short of expectations of the proponents of this idea. Scientists everywhere, and especially in developing countries, should make every effort to publish their work in, and give their full support to, those journals that have adopted the policy proposed in the open letter.

The Public Library of Science also plans to launch online journals that will publish original work in the public domain. The costs will be recovered primarily by charges to authors, which are expected to be approximately $\$ 300$ per published article. Costs will be subsidized for authors from developing countries who cannot afford these charges.

\section{International Scholarly Communications Alliance (www. curl.ac.uk/about/isca.html)}

A new international scholarly communications alliance formed by eight of the world's principal research library organizations in February 2002 will broaden access to research and facilitate transformation of knowledge dissemination. ISCA members - about 600 research libraries worldwide are working together to support equitable access to scholarly literature and to take united action to create appropriate policies. The action-oriented global network will concentrate on ways to ensure open and affordable access to scholarship across national boundaries.

ISCA will engage in a series of activities that focus the scholarly publishing process on the primary goals of the academic research community, advancing the discovery of new knowledge and facilitating its dissemination. Through sharing expertise on scholarly communications issues, these member organizations, whose total library budgets equal over US $\$ 5$ billion and which serve well over 11 million students and faculty, will be prepared to act as a unified body in creating policies and taking actions that advance these goals. Larger libraries in developing countries will do well to coordinate their policies with ISCA.

As a body, ISCA will promote solutions which its members agree are necessary, practical and viable approaches. Among the current advocacy programs are SPARC and the Open Archives initiative.

SPARC (Scholarly Publishing and Academic Resources Coalition, www.sparc.org) is an ARL-initiated effort to facilitate competition in scientific communication through the creation of high-quality low-cost alternatives to expensive commercial titles, and SPARC Europe, recently launched to provide a European operational arm for SPARC activities. SPARC emerged from the widespread perception that in scientific communication the researchers and the laboratories where scientific communication originates - have been forgotten or sidelined and the profit motive of commercial publishers has taken over. SPARC's avowed aim is to restore the researcher in research publishing. SPARC persuades editors and editorial board members of unduly expensive commercial journals to come out and start new journals of high quality. SPARC journals have become popular within a few years of their first publication.

Developing country scientists should submit their work to SPARC journals rather than to the expensive journals they are trying to replace.

Open Archives Initiative (OAI) (www.openarchives.org) develops and promotes interoperability standards to facilitate the efficient dissemination of content. Supported by the Digital Library Federation, Coalition for Networked Information and National Science Foundation, the OAI has its roots in an effort to enhance access to e-print archives as a means of increasing the availability of scholarly communication. The fundamental technological framework and standards that are developing to support this work promise to have much broader relevance in opening up access to a range of digital materials.

The full-text physics archive, arXive, founded by Paul Ginsparg at Los Alamos in 1991, is probably the oldest and 
the most prominent subject-specific e-print server. With more than 15 mirror sites around the world this automated electronic archive covers research papers in physics, mathematics, nonlinear sciences, computational linguistics and neuroscience. arXive contains about 140,000 free full-text research papers, of which about half are in astrophysics and high energy physics.

This pioneering effort is easily one of the most innovative and successful experiments to-date in scholarly communication. Among other examples of successful and varied archive efforts are the SPIRES HEP literature database; the Digital Library for Physics, Astrophysics and Instrumentations (http:// adswww.Harvard.edu); Research Index or Cite Seer (computer science); Cogprints (cognitive science); Clinmed (clinmednet prints.org); RePEc (economics); and CoRR (computing).

Electronic e-prints do not aim merely to capture the articles; they are far more than simple electronic reproductions of what would appear in print journals. E-print publication on the Web offers numerous value-added elements, such as multimedia and data sets, as well as contextual links to other documents referred to in a paper and to databases. Indeed, digital libraries, commercial aggregators of journals and secondary service providers such as ISI and Chemical Abstracts Service, are exploiting the document linking advantage. In the very near future, the print versions of journals will not be the true archivers. The e-print archives, as both the data and the access systems can be mirrored in several locations around the world, offer built-in insurance against possible loss of archived material due to unforeseen calamities (such as natural disasters or system failures at any one location).

For some reason, e-print archives in fields other than physics and computer science are not growing fast enough despite some well-meaning efforts. Stevan Harnad of the University of Southampton says the reason is that disciplines are not the right agent for change. "The right entity for all of this is the university," says Harnad, an outspoken proponent of open access to scientific literature. According to him, universities have an economic incentive to try to reduce the cost of scientific publishing. A number of leading American universities are creating and maintaining institutional archives. These include the Dspace initiative of MIT, the OSU Knowledge Bank of Ohio State University, the Scholarship Repository of the University of California system and Caltech's institutional repository.

Developing country scientists should use the existing archives to disseminate their work as well as to learn about the work of others. They may also establish institutional archives and national level e-print servers, especially in fields such as agriculture and health sciences. Indian Institute of Science, Bangalore, has just initiated its institutional e-prints archive.

PubMed Central (www.pubmedcentral.gov) is a digital archive of life sciences journal literature, developed and man- aged by the National Center for Biotechnology Information (NCBI) at the U.S. National Library of Medicine (NLM). With PubMed Central, NCBI is taking the lead in preserving and maintaining open access to the electronic literature, just as NLM has done for decades with the printed biomedical literature. PubMed Central aims to fill the role of a world-class library in the digital age. It is not, and has no intention of becoming, a journal publisher. Access to PubMed Central is free and unrestricted.

The value of PubMed Central, in addition to its role as an archive, lies in what can be done when data from diverse sources is stored in a common format in a single repository. You get more rapid searching, manipulation and cross-linking of the complete collection and all the benefits that derive from that.

Many journals already have online publishing operations, and there is a growing tendency to publish material online only, to the exclusion of print. This literature must be preserved in a form that ensures open access to it over the longer term. This is what NCBI has undertaken to do. Scientists from developing countries should encourage all journals to join such efforts.

\section{Journals}

A number of journals and archives are now available free on the Web. The Association of Research Libraries has published a Directory of Electronic Journals, which lists several hundred titles that provide free access.

The Open Society Institute (Soros Foundation, www. soros.org/openaccess), founded by the millionaire George Soros, has issued a statement advocating open access and has provided \$3 million over three years for projects supporting alternative journals and open archiving initiatives.

The African Virtual University is a "university without walls" that uses modern ICTs to give institutions in subSaharan Africa direct access to some high quality learning resources. It provides students and professionals in 17 countries free e-mail accounts and access to an online digital library with over 1,000 full-text journals.

\section{Non-Profit Initiatives}

There are a few non-profit publishers/distributors of developing country journals and information. These include Bioline International (www.bioline.org.br), which hosts electronic versions of many developing country journals (most of them at a modest subscription fee); International Network for the Availability of Scientific Publications, or INASP (www.inasp.info/index.html), a co-operative network of partners whose mission is to enhance the flow of information within and between countries, especially those with less developed systems of publication and dissemination; SciELO (www.scielo.org), which hosts more than 80 journals published in Latin American countries, such as Brazil, Chile, Costa Rica and Cuba, and Spain; and African Journals Online 
or AJOL (www.inasp.info/ajol/index.html), which provides free online access to titles and abstracts of more than 60 African journals and full text on request.

HINARI (Health Internet, www.healthinternetwork.org), a UN/WHO initiative, aims to provide commercial medical journals free to licensed countries in the developing world. PERI (Programme for the Enhancement of Research Information, www.inasp.info/peri/index.html), promoted by the INASP, supports information production, access and dissemination for research partners in developing and transitional countries utilizing information and communication technologies.

The Electronic Publishing Trust for Development (EPT), established in 1996, facilitates open access to the world's scholarly literature and the electronic publication of bioscience journals from countries experiencing difficulties with traditional publication. The main activities of EPT are to provide awareness of the benefits of electronic publishing, transfer epublishing technology through training and online resources, provide management and distribution support, and support open access initiatives and make them known to developing country scientists and publishers.

\section{What Needs to Be Done?}

What we want to achieve is to make scientific and technical information flow freely and be accessible at affordable costs to researchers and students everywhere in the world a kind of enlightened socialism for scientific knowledge. To be honest, this can only be an ideal - the direction in which we should move. Achieving this goal would necessarily mean exploring many possibilities. First, we should try to facilitate access to all the content (scientific and technical journal papers, reports, theses, conference papers, bibliographic, factual and full-text information, etc.); second, we should ensure all potential users of this content have access to the technological tools to access it (such as high bandwidth Internet connection); third, we should continue with our efforts to evolve standards and norms, including research into better ways of doing things, that will enhance the ease of use and value of the content; fourth we should build organizational structures that would ensure the long-term survival of the entire system.

As we saw in the previous section, there have been many efforts to enhance free and low-cost access to content of different kinds. A number of journals are available for free access a few months after publication. Many high-impact journals are given such delayed access by High Wire Press of Stanford University. Parts of certain journals, such as The Economist and The New Scientist, are available free on the Web.

Scientists in developing countries and organizations that care for their welfare such as the Third World Academy of Science and the Inter Academy Panel should bring pressure on publishers to make electronic access to their journals free or at least make them freely available a few months after publication. They should support the Public Library of Science movement.
Unfortunately, established publishers would not like to lose their stranglehold on the scholarly journals market and would try to scuttle the open source movement. For example Ingenta, a leading for-profit aggregator of electronic journals, has roped in half-a-dozen champions of the open source movement to be on their advisory board.

A few months ago the Director General of WHO, Gro Harlem Brundtland, and the editor of BMJ, Richard Smith, negotiated a deal with leading publishers of biomedical journals, to make their journals freely accessible to public institutions, universities and hospitals in more than 100 developing countries. The main criterion for selection of countries was per capita GDP of less than $\$ 1,000$. But the publishers did not extend the benefit to several countries that met this criterion (e.g., India, Pakistan and Bangladesh), on the grounds that they already have many subscribers in those countries and they would lose business. In essence, they are willing to give free access to their journals to countries where there are hardly any users - a case of having their cake and eating it, too. WHO should renegotiate the terms and enable all developing countries to gain free access to these journals.

Organizations such as the United Nations Food and Agricultural Organization and ISNAR may take the lead for working out similar arrangements for developing country institutions to gain free access to agricultural (and related) journals. The Inter Academy Panel (IAP), formed by over 80 science academies of the world, can lend its support to such a move.

It is not just the commercial publishers who are making it difficult for developing country scientists to gain free access to information. Even some society publishers are unwilling to throw open access to their journals, largely because subscription to their journals is their major source of income. Nor do they always require scientists affiliated with commercial firms to deposit their data in a public database such as GenBank, thus sacrificing the interest of public good at the altar of commercial interests.

The U.S. National Academy of Sciences (NAS) is a model for other societies and academies. Not only the Academy's Proceedings but also its entire collection of over 2,000 reports are available free on the Web to developing country users. Indeed, Bruce Alberts, NAS president, is a great champion of the cause of science and technology in developing countries. He played an important role in founding the Inter Academy Panel and the Inter Academy Council. Alberts suggested the following two-part strategy in his presidential address to the Fellows at the NAS $136^{\text {th }}$ Annual Meeting in April 1999:

- Connect all scientists to the World Wide Web, by providing subsidized Internet access through commercial satellite networks;

- Take responsibility for generating a rich array of scientifically validated knowledge resources, made available free on the Web, in preparation for a time when universal 
Internet access for scientists is achieved in both developing and industrialized nations.

Both of these are excellent suggestions. Not only do we need useful content to be available free on the Web, but we also need the technology in place to take advantage of the content. A concerted effort should be mounted to persuade philanthropic foundations and donor agencies concerned with higher education and research to donate funds to make available PCs and high bandwidth Internet connections to researchers and libraries in developing countries. The concerned governments should make things easy for the spread of ICTs among university and research institutions, although such installation is easier said than done.

There is a great need for building awareness among Third World researchers and research managers about such tools as electronic journals and open archives and the benefits of networking. Open access evangelists like Steve Harnad should address scientists and scholars in important centers of research in the Third World. A reader on the advantages of going electronic and current developments must be produced and circulated widely. Librarians in the Third World should be given special training to play their role of information intermediaries in the changed circumstances. In short, the transition from print-based access to electronic information access in the Third World should be facilitated by lectures, workshops, training programs and hands on experience as well as through provision of the technical backup.

While agencies such as EPT and INASP can help with the training programs, organizations such as IAP, IAC and NAS can persuade the scientific communities and the governments in the Third World to overcome any inertia or barriers to the transition. Donor agencies such as IDRC and the Soros Foundation can make the necessary investments to make the transition happen soon. If all this can happen, then access to information for research will truly become democratic and the divide between the rich and the poor would be considerably reduced.

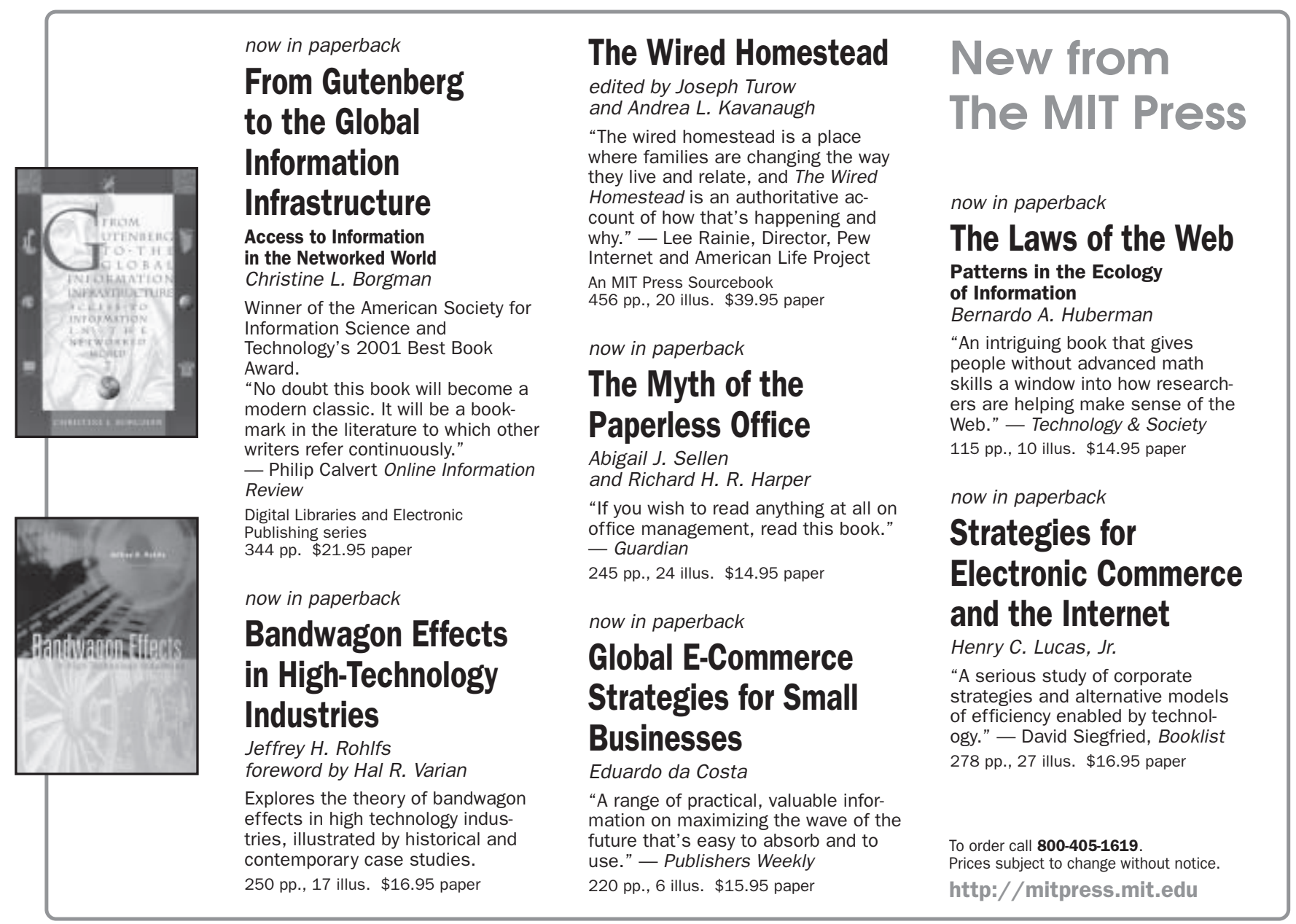

